\title{
Hereditary renal hypouricemia
}

INSERM

\section{Source}

INSERM. (1999). Orphanet: an online rare disease and orphan drug data base. Hereditary renal hypouricemia. ORPHA:94088

Hereditary renal hypouricemia $(\mathrm{HRH})$ is a rare autosomal recessively inherited renal membrane transport disorder affecting urate reabsorption in the proximal tubules leading to usually asymptomatic hypouricemia and predisposing to urolithiasis and exercise induced acute renal failure (EIARF). 